\title{
Exploring a Music-based Intervention Entitled "Portrait Song" in School Music Therapy:
}

\section{Stella Lerner's Song-based Approach}

\author{
Rivka Elkoshi ${ }^{1 \text { * }}$ \\ 1 Levinsky College of Education, Tel Aviv, Israel \\ *elkoshi1@bezeqint.net \\ Received: 19 August 2020 Accepted: 30 September 2021 Published: 1 November 2021 \\ Editor: Michael Viega Reviewers: Joanna Parsons, Alan Turry
}

\begin{abstract}
Songwriting has gained footing as one of the main approaches in music therapy. Many of the publications focus on various techniques whereby children and adults are assisted, individually or in groups, to create songs collaboratively. This study explored a non-collaborative song-based intervention entitled "Portrait Song"; namely, an original song composed by the therapist for and about specific recipients as a therapeutic tool. The "Portrait Song" intervention was initiated and implemented by Ms. Stella Lerner, an Israeli music therapist and composer. Two specific aims were set for the study: (1) to explore the nature of the "Portrait Song" practice as a means for school music therapy; and (2) to examine the effect of the "Portrait Song" intervention on students' outcomes. The author/researcher acted as an outside observer, evaluating the "Portrait Song" intervention and the students' experiences in two schools in Israel, which provide music therapy programs for children possessing a broad range of disorders. Data included field notes compiled during class observations, extensive interviews with the therapist, and examination of musical scores and written material. The study showed that the "Portrait Songs" intervention guided participants to higher levels of social adjustment, refined physical skills, and assisted with areas of self-identity and self-efficacy. Lerner's innovative "Portrait Song" intervention can give music therapists some perspectives about the possibility and benefits of composing complete therapeutic songs (lyrics and music) for and about specific clients in school settings.
\end{abstract}

Keywords: songwriting, school music therapy, song composition, school ethnography, music-based intervention

\section{Introduction}

Songwriting has gained footing as one of the main approaches in music therapy. Many of the publications cited above (endnote i) have focused on various techniques whereby children and adults are assisted, individually or in groups, to create songs collab- 
oratively (e.g., Baker et al., 2018; Edgerton, 1990; Nordoff \& Robbins, 1962, 1968, 2007). This study explored a non-collaborative song-based intervention entitled "Portrait Song." It is an original song composed by the therapist for and about specific recipients as a therapeutic tool in school settings. Through ethnographic methods (i.e., field observations and interviews), the author, who is not a music therapist, aimed to study the way compositional song concepts are realized in music therapy. It was the author's belief that the results of an ethnographic study may have relevance for both music therapists and music educators.

The following review of the literature focuses on two relevant topics: (1) Songwriting practices in music therapy; (2) Songwriting practices in school settings.

\section{Songwriting Practices in Music Therapy}

Former studies in the field of music therapy (e.g., Baker et al., 2018; Gfeller, 1987; Nordoff \& Robbins, 2007; Plach, 1980), music sociology and group therapy (e.g., Ansdell, 2014; Jones, 2005; Wilson, 2013), psychotherapy (Dalton \& Krout, 2005; Ficken, 1976; Silverman, 2011), and music education (Derrington, 2005,, 2011; Kratus, 2016; Riley, 2012) pointed toward the positive impact that songwriting had on participants' well-being, communication, socialization, and processing of feelings. For example, songwriting met clients' varying physical, emotional, and cognitive needs (Aigen, 2009; Baker et al., 2018; Wilson, 2013); promoted social interaction (Ficken, 1976; Gfeller, 1987; Nordoff \& Robbins, 2007; Plach, 1980) and provided joy, happiness, and enjoyment (Jones, 2005; Silverman, 2011).

Songwriting procedures encompass various techniques whereby children and adults are assisted, individually or in groups, to create songs collaboratively (Baker et al., 2009; Nordoff \& Robbins, 2007; Aasgaard \& Blichfeldt Ærø, 2016). Music therapists typically helped clients in writing lyrics and composing music (Bruscia, 1996).

A variety of lyric-based methods were used in which a preconceived song functioned as the structural framework to which individuals rewrote new lyrics. Through replacement (substitution) of individualized narratives in pre-existing songs, participants were given a chance to project personal situations, thoughts, feelings, and interests. Lyricbased methods include parody, cloze procedure, word starters, word lists, collage, and rapping. Music-based methods were also used, including blues song structures (Goldstein, 1990; Schmidt, 1983); pastiche (Baker et al., 2008; Baker, 2015; Roberts, 2006), and improvising and recording via software equipment (Dalton \& Krout, 2017).

\section{Music and Lyrics}

Researchers examined the multi-faceted ways in which words and music interact in improvised songs and instrumental music (e.g., Ansdell 1995; Baker et al., 2009; Brown \& Pavlicevic, 1997; Lee, 2003; Streeter, 1999; Turry, 2006). Some therapists/researchers based their conclusions on an analysis of the lyric content mainly (e.g., Bailey, 1984). Others advocated an'absolutist' position, promoting the importance of musical analysis both in clinical and research work (e.g., Ansdell 1995; Brown \& Pavlicevic, 1997; Lee, 2003). Streeter (1999) objected to the 'absolutist' position proposing an integrated approach, and Turry (2006) likewise emphasized the fusion of words and music for maximum therapeutic benefit:

The combination of words and music helps to integrate cognitive and affective processes. (p. 38)

It is both the structure of the music and the drama enacted by the music and words together that the listener responds to. (p. 67)

However, we recall that music consists not only of words and music but of multiple semiotic systems. Music includes visual and gestural systems, in addition to words and sounds. Inaudible and non-verbal communication affords information for the musiccentered therapist. The relative importance of any semiotic system (verbal-audible- 
visual) can fluctuate according to changing therapeutic conditions and needs while considering songs for therapy.

\section{Songwriting of the Nordoff-Robbins Music Therapy (NRMT)}

Songs for individuals (children and adolescents) with special needs were improvised and published by Paul Nordoff (1909-1977) and Clive Robbins (1927-2011) between 1959-1974 (Nordoff \& Robbins, 1962, 1968). Nordoff, an American composer/therapist, and Robbins, a special educator, developed the Nordoff-Robbins Music Therapy (NRMT) approach. NRMT was described as "a novel music-centered approach based on therapists' creativity and sensitivity, which emphasized listening deeply to clients' nonverbal, verbal, and musical expressions, improvising aesthetically powerful and clinically effective compositional musical forms" (Turry, 2014, p. 1). The NRMT repertoire of songs (and instrumental pieces) functioned as a didactic and practical resource for music therapy students, educators, and clinicians. It became a "model of musical form fashioned with developmental challenges embedded within" (Ritholz, 2014, p. 9).

NRMT emphasized the clinical benefits inherent in the unfolding creative process of songwriting among individuals with special needs. Nordoff and Robbins (2007) wrote about the emergence of communication, social interaction, and coactivity. Turry (2014) attested:

Nordoff and Robbins harnessed the power of music to evoke new developments in children, and the results were often astonishing. (p. 1)

The idea that improvising songs can have a direct and transformative effect is one of the basic tenets of the Nordoff-Robbins approach to music therapy... moving the child away from pathology and toward a new developmental level. (p. 346)

Nordoff-Robbins therapists/composers continued the NRMT songwriting legacy with various client populations, including adults (e.g., Ansdell, 1995; Lee, 2003; Lee \& Houde, 2011; Turry, 2014). Research studies emerged. Nordoff and Robbins (2007) interrogated the detail of their own cases through observational descriptions and microanalyses of audio and video recordings (Ansdell, 2010), and therapists/researchers explored the NRMT ontology and clinical effects through case studies mostly ${ }^{\text {ii }}$ (e.g., Aigen, 1997, 1998; Aldridge, 2005; Ansdell, 2010, 2014; Ritholz, 2014; Robarts, 2003; Turry, 2006, 2009, 2010). NRMT studies indicated therapeutic improvements and changes toward well-being (e.g., Aigen, 1998; Ritholz, 2014; Turry, 2006, 2009). For example, Aigen (1998) demonstrated that rhythmical music, employed with the conceptual foundations of NRMT, had benefits in cognition, affect regulation and motor skills. Improvement in psychological processes was manifested in Turry's (2009) work, as improvised songs allowed the therapist "to guide and alter [the client's] psychological process while offering a creative vehicle of expression" (p. 2).

Attempting to standardize NRMT while preserving "the core spirit of individual creativity essential to clinical work" (Turry, 2014, p. 4) caused tension and ongoing debates among therapists. Therapists/researchers prompted the importance of utilizing Nordoff-Robbins compositions flexibly while responding to the emerging needs of clients that arise spontaneously in sessions (e.g., Aigen, 1998; Ritholz, 2014). Nevertheless, the Nordoff-Robbins view of songs remained central, and so did the notion that songs created within music therapy experiences can meet therapeutic goals.

\section{Compositional Teamwork}

As noted above, researchers have found advantages in collaborative songwriting. However, theorists presented problems compositional teamwork generated (Abra, 1994; Barrett, 2014; Gromko, 1996; Moran \& John-Steiner, 2004). Abra (1994) considered personal disparity, dominance struggles, controversy, and unreachable consensus within compositional teamwork. Moran and John-Steiner (2004) witnessed problems of "impatience, ownership, conflict, and unfriendliness" (p. 19) caused by collaborative 
composition. Gromko (1996) found that questions during side-by-side-with-researcher compositional work "often led participants to places where they would otherwise not have gone" (p. 49). Barrett (2014) concluded that collaborative composition is fraught with disagreements, tension, and contradiction.

However, these disadvantages in compositional teamwork were detected by teachers/researchers rather than music therapists, at mainstream institutional settings rather than clinical settings. In music therapy settings, conflicts could be considered important and helpful in advancing children towards interpersonal improvement. Aigen (1997), for example, found that periods of conflict among clients and between clients and therapists led to enhanced cohesiveness and individual growth among adolescents with developmental delays. During a year-long process of group music therapy, the participants developed an individualized repertoire of songs that reflected the interpersonal process at each stage of development. This shows that the context of research settings can significantly influence the extent and capacity of children's self-expression and disclosure (Smith et al., 2005).

This research focuses on a songwriting practice implemented in specific therapeutic school settings in Israel. Unlike the studies cited above, the "Portrait Song" practice is declared non-collaborative. It is wholly created by the therapist (lyrics and music) and taught by rote to target clients for therapeutic purposes. Studying this technique in specific Israeli school settings may contribute to a research area with scarce information.

\section{Songwriting Practices in School Settings}

Former studies showed that collaborative songwriting methods in school settings empower the students' learning and well-being (Baker, 2015, 2016; Draves, 2008; Swanson, 2020). It was argued that songwriting connects directly with schoolchildren's culture (Derrington, 2005, 2011; Draves, 2008; Kratus, 2016; Riley, 2012); provides an "outlet for self-expression" (Edgerton 1990, p.19), helps bereaved students gain insight into their grief (Dalton \& Krout, 2017), and promotes self-knowledge, self-confidence (Kratus, 2016), self-esteem (Draves, 2008; Edgerton, 1990; Lindberg, 1995), and assertiveness (Lindberg, 1995).

Three lines of songwriting attitudes are discernable in the literature: the main approach which involves music therapists facilitating clients' songwriting, lyrics, and melodies; (Baker et al., 2008; Edgerton, 1990; Goldstein, 1990; O'Callaghan, 1996; Priestley, 1985; Schmidt, 1983); a second approach involves music therapists setting to music the lyrics that their students created (Jones, 2006; Lane, 1988); and a third approach, occupying a relatively small place in the literature, that involves music therapists creating complete therapeutic songs (lyrics and music) for their clients (Jones, 2006).

The "Portrait Song" procedure, which is the focus of this study, belongs to the third line of songwriting attitudes, namely non-collaborative therapeutic songs created by the music therapist for and about specific school recipients. The implementation of Lerner's teacher-centered songwriting approach in Israeli music therapy schools provided an opportunity to research this particular approach. In general, music therapy research in Israel is less developed than clinical work (Amir, 2001). As a music teacher/ researcher, the author wished to look into the therapeutic non-collaborative songwriting approach and its implementation in Israeli school settings.

This ethnographic study examined for the first time the "Portrait Song" intervention as a unique non-collaborative therapeutic songwriting approach implemented in Israeli schools with children possessing a broad range of disorders. This study may contribute to the increasing body of knowledge of songwriting practices in music therapy.

\section{Purpose}

The general purpose was to explore the therapeutic "Portrait Song" intervention as initiated and implemented by Ms. Stella Lerner, an Israeli music therapist and compos- 
er, working in two Israeli schools for students possessing a broad range of disorders. (More details about the music therapist and the research sites below.)

Two specific aims were set for the study:

1. To explore the nature of the "Portrait Song" approach as a means for music therapy, and

2. To examine the effect of the "Portrait Song" intervention on students' outcomes.

Two related research questions were asked:

1. What is the nature of the "Portrait Song" approach?

2. What is the impact of the "Portrait Song" intervention on schoolchildren with special needs?

\section{Method}

\section{Type of Study}

The study is a qualitative ethnographic case study (Gay et al., 2011; Stake, 2005). It is defined as school ethnography (Gay et al., p. 426) since it explores the therapeutic songwriting intervention in school settings. The study is a particularistic case study as it focuses on a bounded phenomenon (Stake, 2005), the non-collaborative "Portrait Song," implemented in particular settings by a single individual.

\section{Data Collection, Sources, and Techniques}

For methodological triangulation in a qualitative study (Gay et al., 2011), the author used multiple data sources: class observation, unstructured interviews, and examination of audio and written sources.

\section{Class Observations}

The researcher grew interested in therapeutic aspects of songwriting implemented in educational settings. Taking on the role of a passive observer, the researcher focused on collecting data through extended fieldwork (Gay et al., 2011). Seven class observations, 50 minutes each, and three school concerts about one hour each were observed over the course of two school years (2018/2019, and 2019/2020). The researcher followed an ideal expressed by Zaare (2012): "Observers are not evaluators or intruders who come to assess how well a teacher teaches, but peers who come to learn from classroom events" (p. 611). All field notes were written on-site and compiled after leaving the settings.

\section{Unstructured Interviews}

Data collection relies on face-to-face informal interviews with the therapist/composer to elicit information about her educational and therapeutic perspectives, goals, and past experiences. Six interviews (of 90-120 minutes each) were taped and later transcribed, coupled with phone calls and email conversations.

\section{Audio and Written Sources}

Data included tape-recorded songs, videos of "Portrait Song" sessions, musical scores, and written documents: schools' published material and the therapist syllabuses, abstracts, and notes. This data was often used as a starting point for subsequent class observations.

\section{Data Analysis}

The resulting analysis is a description of emergent themes, codes, and thought-patterns (e.g., Allwright, 1988; Gay et al., 2011; Zaare, 2012). Interpretations are grounded in the data through the use of direct quotes from the therapist and class members. 


\section{The Music Therapist and her Therapeutic Position}

Lerner is a trained music therapist. She achieved her Master's in special education, musicology, and linguistics from Immanuel Kant Baltic Federal University in Kaliningrad (formerly Königsberg), Russia, and a license to practice music therapy in schools for special education from the Israeli Ministry of Education. As a composer, her musical output includes songs (e.g., Stella Lerner: Poetic Songs, 2016) and chamber music, published by the Israel Music Institution and played on the radio in Israel and abroad. Since 1992 she has worked with Israeli school children with physical, behavioral, mental, and emotional problems. Her passion is helping children with special needs through "Portrait Songs," and she has worked in this field since 1994. Lerner's therapeutic work is rooted mostly in the principles of behavioral therapy. Her outspoken aim is to alter (or minimize) undesirable (problematic) behaviors and reinforce healthy ones. The "Portrait Song" program is the means for achieving these goals.

\section{The Author}

As a music teacher/researcher, trained and certified in the Orff and OMT (Orff Music Therapy) approaches, the author's curiosity was twofold: to inspect the non-collaborative songwriting phenomenon in her cultural surrounding and to learn about its therapeutic effects.

\section{The Research Sites}

For diversity sampling, the "Portrait Song" intervention was observed in two Israeli schools. ${ }^{\text {iii }}$ The following information about the schools is cited from the schools' documents [Hebrew].

[School-A] has about 100 students. The school is for children with developmental, mental, and motor disabilities, related complex disabilities, verbal, communication, CP, autism spectrum disorder, sensory disabilities, and various congenital syndromes.

[School-B] is a state elementary school. It has about 300 students. Students with special needs, such as mental disorders, emotional disturbances, and cognitive impairments, are either integrated into mainstream classes or learn separately in small classes... Music therapy is provided for students with special needs. (Translated by the author.)

\section{Study Approvals and Ethics}

This study received approval from a local Institutional Review Board in central Israel. Ethical approval for this research was granted by the authorities of the schools (schoolA and school-B) to attend Lerner's "Portrait Song" classes. Lerner had informed her students that the school has a policy that teachers can be observed in the classroom, and receive feedback on their teaching. Photographs or videos were not used during class observations. Pseudonyms are used in the report to ensure children's confidentiality. Lerner obtained a consent note for the current report.

\section{Respondent Validation}

Lerner read through the data and analyses and provided feedback on the author's reflections and interpretations of her responses.

\section{Data Examples}

The following vignettes provide a glance into Lerner's "Portrait Song" intervention and her pupils' experiences. Each vignette is followed by the author's interpretation of the respective events. The songs were arranged for YouTube. Scores and YouTube links are presented in Appendix I. ${ }^{\text {iv }}$ The author translated the Hebrew lyrics for this report, attempting to be as faithful as possible to the syllabic verses and the content of the songs. 


\section{Vignette 1: Rehearsing for a Concert}

During the last week of school, the author attended a group rehearsal for an end-ofthe-year event. Lerner had explained the purpose of the concert a few days earlier when she called to invite the author to the rehearsal: "The concert is a time for the children to sing on stage! More of a new challenge for them; a time for the audience, parents, and staff to acknowledge their achievements!" The rehearsal took place at the School-B auditorium. It was a large venue with seating for about a hundred and a large stage equipped with an electric keyboard. Lerner introduced her pupils: Shirley, Regina, Natasha, Diana (girls), and Marius (boy), all sixth-graders, who study in a special education class, and Barack (boy) from a mainstream-class who joined the group. The children seemingly shy and reserved clustered near the stairs leading to the stage, awaiting their turn to go on stage and sing together two of Lerner's "Portrait Songs."

\section{Reflections: End of the Year Event as a Termination Process}

Music therapy authors stressed the importance of implementing a constructive termination process in music therapy to accelerate clients' therapeutic growth (Fortune, 1987; Hudgins, 2013; Wheeler et al., 2005). As a termination event, the end-of-theyear concert was important not only for presenting in public the children's achievements but introducing a new educational challenge, singing on stage for the first time. Thus the therapist turned the termination process into a constructive learning experience, a learning step rather than a stop.

\section{Vignette 2: "Rejoice" and "Friendship"}

The children are on stage and Lerner at the keyboard. They perform the first song "Rejoice," which according to Lerner, had been composed as a song of optimism, joy, and well-being for children of any abilities. Starting with an anacrusis on the V-I, the fast tempo (con moto), rhythmic/harmonic energy in a major key (F), grounding tonicdominant bass motif, and ascending melodic phrases, should enhance happiness and joy, affirming the declaration: "We came to rejoice...it's good to sing!" However, the children seem uncomfortable singing on stage. Lerner wants them to express joy. She announces enthusiastically: "Rejoice is a happy song! I want you to be happy, with a smile spanning all over town!" Lerner sings in exultation: We came to rejoice, we came to chant / Smile happily; don't say you can't." She then plays the short introduction in swing, and the choir joins in with more confidence and an expression of joy. The second concert song entitled "Friendship" follows. It is a lyrical legato song in slow tempo, oscillating between a major key and the parallel minor (C-Am), with an overall descending contour.

See Appendix I for the scores and Youtube links of "Rejoice" and "Friendship".

\section{Reflections: A Stimulative Song and Teacher Modeling}

Expressing joy through songs is a universal phenomenon from ancient biblical times, "up to the modern hospital and balcony songs, ${ }^{\mathrm{vi}}$ performed during the 2020 corona-virus pandemic (Clinch, 2020; Janglo News, 2020). Researchers have noticed that "singing is a spiritual practice-it offers the possibility of transforming energy-to have an experience of your whole self" (Bepko \& Kresten, 1993, p. 118). Joy is an experience that is emphasized by Nordoff and Robbins (2007). They point out how important this state is as a trigger for self-actualizing experiences that are transformative for clients (Turry, 1998).

Two songs of contrasting temporal patterning-the fast "Rejoice"and the slower "Friendship"—had a different effect on the children's body language. The simulative "Rejoice" made children more alert, while the slower "Friendship" relaxed their singing, making them look rather soothed. It has been confirmed that singers and listeners experience optimistic and melancholic moods with stimulative and sedative musical stimuli, respectively (e.g., Biller et al., 1974; Smith \& Morris, 1976). "Temporal pat- 
terning seems to have, through either development or evolution, the capacity to evoke a variety of experiential states" (Bharucha et al., 2006, p. 143).

By showing intense enthusiasm while demonstrating the way "Rejoice" should be performed, Lerner practices teacher modeling. Her demonstration was coupled with verbalization about the song's lyrics (a cognitive element) to make the musical interpretation clear and learnable. Through modeling and verbalization, the music therapist enabled transitions in both demeanor and musical expression, from alert expression to apparently rejoicing in "Rejoice." Influential music educators ${ }^{\text {vii }}$ and psychologists ${ }^{\text {viii }}$ have long advocated teacher modeling as a powerful research-based tool to enhance music education (Dickey, 1992), particularly with performing ensembles (Haston, 2007). It is endorsed that a good public performance is not only the performers' chance to be esteemed but can lead to positive feelings of competence and self-efficacy in the long run.

\section{Vignette 3: "What Do You Think?"}

The rehearsal is over. Children get off the stage. Lerner moves chairs to a circle and instigates a conversation. She non-specifically asks: "What do you think?" While sitting in the back, trying to be as unobtrusive as possible, I jotted down the children's exchanging comments.

Shirley said: "The 'Friendship' song gives me a good feeling. We want to be someone's good friend. I have a real friend from childhood. We were born in the same hospital. We were in the same kindergarten, and now we're in the same school."

Marius comments: "The 'Friendship' song is fun! It's fun! I dream about having friends. I like playing Knights with my friends. I have a friend his name is Roy. I have another friend and he is here - Barack. He is a smart boy."

Regina said sadly: "This song ['Friendship'] speaks of something that you don't have, and you want to have it. As if you want to play with friends but they don't agree."

Diana: "There is a girl who doesn't want to be my friend. The song ['Friendship'] makes me sad."

Barack: "The song 'Friendship' is weak. ${ }^{\text {ix }}$ You can't dance to it! I like rhythmic music because it's faster. 'Rejoice' is rhythmic. One hears the rap in it. I like to dance to it."

Diana: "The happy song sounds better."

Natasha: "I like it when Stella plays fast, but I don't like slow music. I like the happy song better. There are parts that I like to sing."

Regina: "In the gym, we exercise fast. When the music is slow I simply turn it off. Dogs are sportive and fast. I dream of having a dog."

\section{Reflections: Social Functioning}

While the singing session was under Lerner's control, the verbal session that followed was conducted without specific guidance, a condition that sparked interactions and new relational possibilities. Bailey (1984) asserted that songs have the potential to establish human contact and provide a framework for enhanced communication, "as singers and listeners alike can relate to the self-expressive qualities of songs" (p. 7).

There was no consensus about the aesthetic-musical value of each of the concert songs. "Music is often supposed to affect judgment and evaluation... no two children have the same opinion and taste" (Scherer \& Zentner, 2001, p. 373). Children in group therapy "benefit from learning to both compete and compromise, to fight and settle fights, and to bargain and to compromise" (Grundblatt, 2016, p. 25).

While discussing the song "Friendship," children related to its verbal content. The lyrics of the song evoked contrasting affective and emotional outcomes: "emotional involvement is inevitably part of any musical interaction" (Rolvsjord, 2005, p. 98). For 


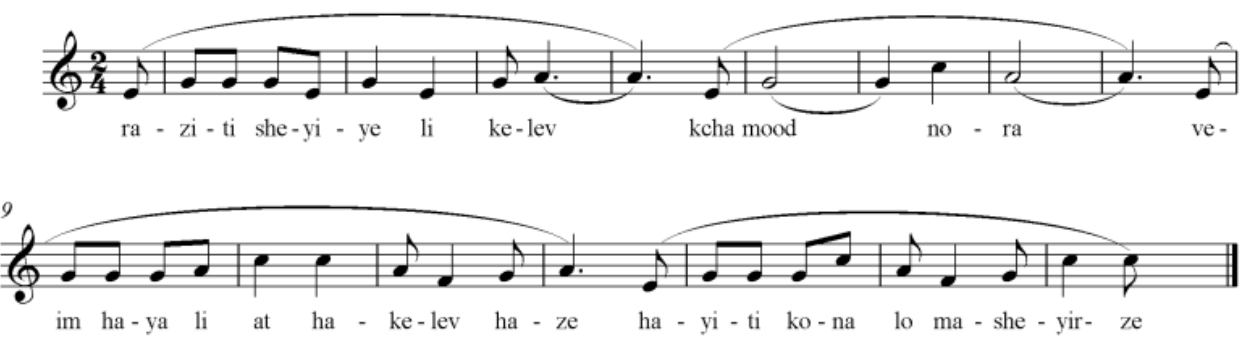

Figure 1

Stella's improvisations

some children, the song was "fun!" (Marius) and evoked "a good feeling" (Shirley); for others, it caused "sadness" (Regina) or seemed "weak" because "you can't dance to it" (Barack). The different emotions that were elicited by the song "Friendship" stem from different personalized connections to its verbal content. The song became a means "to transcend everyday reality and contact the transpersonal spiritual dimensions of life" (Austin, 1999, p. 143). The children discussed the way friendship as a concept is relevant to their personalized social life and expressed their feeling about having (or not having) friends. Some children identified joy through the song as the verbal message met fulfilled social experiences in their lives: "I have a real friend" (Shirley); "I like playing Knights with my friends" (Marius). Other children identified sadness when the verbal message met unfulfilled social functioning: "the song speaks of something that you don't have" (Regina), and "there is a girl who doesn't want to be my friend." Thus discussing "Friendship" became a personalized, emotion-eliciting event, "a direct way to contact and express intense feelings" (Austin, 1999, p. 143). Bailey (1984) stated that "personalized connections to songs are important to the development of the therapeutic process" (p. 11). "It is in the responding to others that a person communicates his or her individuality and by so doing shapes and develops his or her self" (Robbins, 1991, p. 57). NRTM therapists affirm that songs offer an opportunity to understand the linkages of musical processes with psychological processes (e.g., Turry, 2009).

When referring to the song "Rejoice," children related to the rhythmic aspects of the song rather than the verbal content. While translating rhythmic aspects into physical/ corporeal movement, they unanimously preferred fast over slow tempo and the song "Rejoice" over the song "Friendship": "Rejoice is rhythmic... I like to dance to this song" (Barack); "in the gym, we exercise fast" (Regina). "Inner Motion" is a core experience of music (Repp, 1993), while "movement and dance are natural human responses to music, particularly rhythmic music" (Crowe, 2004, p. 17).

\section{Vignette 5: "I Wish I Had a Dog"}

Lerner said to Regina: "If you want to have a sportive dog, we can make your dream come true through a new song." Lerner started to improvise:

I wish I had a dog;

Together we can jog,

A dog so cute and good,

I'd buy him toys and food.

Regina continued without delay:

And if it wants to poop,

We'll walk out as a group.

Figure 1 and 2 presents the author's transcription of Stella's and Regina's improvisations. 


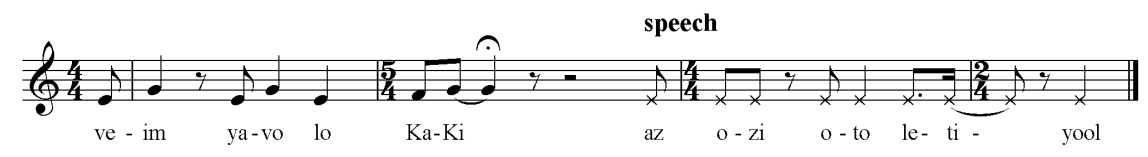

Figure 2

Regina's improvisations

\section{Reflections: Children's Improvisation}

Lerner, as an able improviser, grasped Regina's dream and started a new "Portrait Song." Her musical ideas were spontaneous and professional. Such acute, active listening was exactly what Nordoff and Robbins brought to music therapy, the "Creative Now" that Robbins discussed (Ansdell, 2010, p. 283). Although Lerner asked for no involvement in her improvisation, Regina's involvement occurred spontaneously as a self-initiated activity. Regina echoes the minor-third melodic motif and the syncopated pop rhythms, thus turning a declared non-collaborative songwriting approach into a collaborative activity. Regina's "Poop-Pop" improvisation demonstrates collaboration through modeling, as Zimmerman and Ghozeil (1974) suggested: "The child's responses will be altered as a result of his observation of the model's performance" (p. 440). Baker (2015) assumed that with the support of a therapist, by illustrating improvisation, and by other methods (like FITB and parody) "strategic songwriting can function as a preparation for original songwriting" (p. 108).

\section{Vignette 6: Regina's Dog Was Lost...}

About a year later, during an interview, Lerner was asked if Regina's "Dog Song" had been pursued. Lerner had no recollection of the "Dog Song" improvisations. Lerner was asked if children were ever encouraged to participate in the songwriting process. The answer was negative and metaphorical: "I do not let children compose my songs in the same way that painters do not let their models draw for them. A 'Portrait Song' reflects my vision about the child."

\section{Reflections: The Observer's Insights}

Although Lerner's/Regina's "Dog Song" was forgotten and never completed, it revealed the potential of spontaneous collaborative songwriting. Observational studies (e.g., Allright, 1988; Gebhard, 1999) give the observer insights that are sometimes not observed by the music teacher/therapist when he or she is actively engaging in work.

\section{Vignette 7: The Origins of the Songs "Rejoice" and "Friendship"}

During another interview, Lerner was asked about the recipients of the concert songs "Rejoice" and "Friendship". She replied: "'Rejoice' was not composed for a particular recipient. It's a collective song for everyone; an uplifting song to invoke happy feelings and optimism. However, the song 'Friendship' is a 'Portrait song'. I composed it for Roy, an autistic boy, a second-grader at the time, who ten years ago studied in my class with six other autistic boys. Roy had social problems. He was aggressively courting his classmate David but to no avail, David remained subdued and stiff. In that class, no friendship relations were formed. Roy was angry and frustrated. He would bully children, drop to the floor, and make endless efforts to draw David's attention. He talked constantly, refused to obey instructions, and often ran out of class to hide in the schoolyard in a cardboard box there. He used to say that the world is against him. The song 'Friendship' aimed to teach Roy and David the essence of positive relations. Roy and 
David learned the song together. Through this activity, they transformed and a certain rapport was formed between them."

\title{
Reflections: Types of "Portrait Songs"
}

Lerner's song production is of two types: "Community Songs," such as "Rejoice," which convey messages of hope and optimism "for everyone"; and "Personal Songs," such as "Friendship," for specific recipients to meet their individual needs. In fact, "Community Songs" of hope and optimism are common throughout history. "Hope" ("Hatikva"), the Israeli Anthem, is one example: "Our hope is not yet lost; the hope that is two-thousand years old; to be a free nation." Songs that invoke hope have many psychological benefits for human well-being, including health and cognitive outcomes (Fredrickson, 2001). The individualized "Portrait Song" type is a purposeful song, composed for specific recipients to teach, heal and improve their conditions. Still, there is the intention for individualized "Portrait Songs" to become "Community Songs," through choir singing, concert performance, and recordings. Thus over time, the song "Friendship," which had been composed for Roy and David, became a community song for the concert choir (Vignette 1) and other singers and listeners. Lane (1988) suggested that patients' songs can be used to support other patients who identify with the lyrics.

"Through this activity, they transformed," said Lerner, showing confidence in the power of "Friendship" to bring about behavioral transformation in Roy and David. However, it is not always easy to distinguish between enabling patterns of behavior and transforming them. 'Enabling' can be described as a situation where the music therapist helps the client through a song, but it cannot mean transforming, solving, or making autistic behaviors go away.

\section{Vignette 8: "Dreaming of a Jungle"}

During interviews, Lerner displayed scores and lyrics of individualized "Portrait Songs." Three songs, "Dreaming of a Jungle," "Dressing" and "Comet" that she considered most significant are presented below (Vignettes 8-10).

\begin{abstract}
Lerner displayed another song for Roy, "Dreaming of a Jungle."She said: "Roy told me once: 'I feel like a boy growing up in an urban jungle. I dream of living in the jungle without restrictions.' These words were a source of inspiration for a Ballade, which reflects my empathy for Roy's intelligent and heroic soul. Roy continued: 'When Baloo played with Mowgli.' I understood his meaning right away and used his words for the beginning of the song. Roy, who was always neglected and in the brink, got to be the center of my attention. When I first presented the song he was interested in the lyrics. He liked singing the song. It helped him become more cooperative. He stopped running out of class. He never ran out during my sessions. Colleagues asked me: 'What is your secret with Roy?' I replied: 'Songwriting! It works!' I see into the child during my sessions, and as an artist, I mirror their situation for them. Through this process, the child is 'born anew,' gets an identity, like a documented ID card. He transforms and grows."
\end{abstract}

See Appendix I for the score and Youtube link of "Dreaming of the Jungle."

\section{Reflections: Children's Verbal Sharing and the Use of Metaphor}

Based on "The Jungle Book" (1894), the work of the English novelist Rudyard Kipling (1865-1936), the song "Dreaming of a Jungle" reflects Roy's fantasy; his solidarity with Mowgli's character, the free human-cub raised in the jungle. Roy's metaphor and Lerner's symbolic language convey Roy's situation unobtrusively through a non-threatening "Ballade" that "mirrors Roy's situation." The employment of Roy's words "When Baloo played with Mowgli" at the beginning of the song demonstrates once again (as in Vignette 5) the thin borderline between declared non-collaborative songwriting and children's involvement through self-initiated verbal sharing.

Lerner gave voice to Roy, a child who had been "historically silenced or marginalized" (Brantlinger et al., 2005, p. 199). She expressed great attention, appreciation, and acceptance for Roy as a "wonder child" (in the lyrics) who had never been in focus as 
now when a second song was composed for him and about him; a through-composed song in A-minor, with piano harmonies modulating chromatically in broken chords, reflecting a dream: "a kid...that always dreams ... " When Roy encountered the song for the first time he firstly focused on the lyrics. According to Baker et al., (2009), it is the lyrics that the clients will listen to and relate to, therefore in songwriting, the focus should always first be on the lyrics.

Roy benefited greatly by his second "Portrait Song". He became "more cooperative" and never ran out during Lerner's lessons. The importance and efficacy of song-based work to promote personal growth is well-supported in music therapy literature (e.g., Aigen, 1997, 1998; Baker et al., 2008; Edgerton, 1990; Lindberg, 1995; Nordoff \& Robbins, 2007; O'Callaghan, 1996; Ritholz, 2014; Silverman, 2011; Turry, 2014).

\section{Vignette 9: "Dressing"}

Lerner presented a video of a recorded lesson with Jeff learning to sing the song "Dressing." As Lerner explained, the song aimed to improve Jeff's gross sensory-motor functions. While singing and acting out dressing-a-shirt movements, Jeff moves gradually from slow to more active dressing movements. Lerner tells about Jeff, the song recipient:

Jeff is a child with severe dyspraxia. He failed to perform concrete actions and daily activities. He moved clumsily and was greatly afraid of physical failure. Getting dressed was especially hard for him. I told him: 'In music everything is possible.' As an action song, "Dressing" begins with a dreamy motionless introduction in the minor key, and then, when the action of dressing starts, the tempo accelerates and the key changes to major. The song ends triumphantly "A shirt on my skin, and I am within!" Unexpected harmonies intend to stimulate Jeff's physical activity.

See Appendix I for the score and Youtube link of "Dreaming of the Jungle" and "Dressing."

\section{Reflections: Psychomotor Training}

By singing the song "Dressing" and acting out the movements, Lerner was guiding Jeff to a higher state of physical functioning, wishing to maximize his sensory-motor independence, and reduce frustration and fear of physical failure. The lyrics and the music-a swaying 6/8 meter, harmonic transitions (major-minor), and a gradual tempo change (accelerando)—coaxed Jeff's participation and coactivity. The music binds the words and actions into a complete experience through the binary form (introduction-action). By singing and acting, Jeff moved gradually from slow to more active sensory-motor functions and thereby could overcome physical and mental restrictions. Researchers confirmed that motor and mental coordination can be improved through musical experiences (Aigen, 2009; Hatampour et al., 2011; Stephensen \& Baker, 2011; Turry, 2014). Turry (2014) stated: "Improvised songs can establish a particular quality and then by shifts in elements such as tempo and dynamics change the energetic experience for the client" (p. 359). Aigen (2009) examined the relationship between tonal motion and physical motion in NRMT improvisations and songs. He showed how compositional decisions related to the tasks of clients in achieving physical motion. Jeff's documented lesson shows how a student manages to cope with physical (and mental) restrictions through a songwriting music therapy intervention.

\section{Vignette 10: "The Comet Song"}

The author attends a concert in School-B initiated by Lerner. The program consists of 14 "Portrait Songs" performed either by individuals or groups. Rachel, a third-grader autistic child, refuses to go on stage when her turn comes to sing a song entitled "The Comet Song." Lerner starts singing instead of Rachel in synchronization with a pre-recorded soundtrack of the piano accompaniment. As Lerner reaches the refrain, Rachel appears on stage and continues the song. She knows the song well, with the 
lyrics fully memorized, and she sings in tune. During a subsequent interview, Lerner tells the history of the song:

"The Comet Song" was composed for Rachel, an autistic child, when she was in first-grade. Rachel was constantly on the floor rolling like a cat or walking around while flapping her hands and spinning in circles. She had a shrill voice when she spoke. She preferred to be alone the majority of the time. But looking into Rachel's eyes revealed a spark. The song describes Rachel as a star that can be watched but not reached. To imitate Rachel's movements, the rhythm is rolling in dotted notes. Non-diatonic Neapolitan chords represent the distance and alienation of the star-Rachel. She learned the song quickly and sang accurately.

See Appendix I for the score and Youtube link of "The Comet Song."

\section{Reflections: The Conjunction of Words and Music}

"The Comet Song" is a song in which both the lyrics and the music (vocal and piano parts) function together to portray Rachel's behavior and personality as observed by the therapist. Throughout the song, Rachel is compared to a (musical) star that can be watched but not reached. The star metaphor not only adds poetic interest but precludes from direct reference to social disconnect. Rather than directing desirable class behaviors, the music copies the tempo and rhythms of Rachel's "rolling-like-a-cat movements via a dotted-note melody in 12/8 meter and persistent triplets "rolling" in the piano accompaniment.

\section{Singing in Public-Fight-or-Flight}

Music Performance Anxiety (MPA) is a leading severe medical problem common to many singers (Studer et al., 2011). The author assumes that Rachel refused to come on stage because she experienced high levels of MPA. She preferred flight rather than fight. By beginning to sing in Rachel's place, Lerner practiced a modeling-based strategy. Thereupon Rachel ended the "Comet" performance on a positive note.

\section{Rachel's Singing Success}

Researchers theorized the requisite processes involved in singing success (e.g., Joyner, 1969; Welch, 1986). Joyner (1969) outlined three requisites: pitch discrimination, recalling melodic lines, and having a vocal instrument capable of reproducing melodies. By these criteria, Rachel's singing was a success. She sang in tune, with no shrill-sounding voice, showing a facility for rote memory of melodic lines (and lyrics as well). Additionally, she sang in synchronization with a soundtrack. Thus she manifested an inherent capability of active listening to recorded harmonies. Turry (2014) considered music therapy a means to communicate and relate to children with autism. Studies consistently show the special interest and ability of those with autism to participate successfully in musical activities (e.g., Hardley et al., 2001).

\section{Findings}

The findings are presented in two sections: (1) concepts related to the nature of Lerner's "Portrait Song" intervention; and (2) the impact of the "Portrait Song" intervention on Lerner's pupils.

\section{The Nature of Lerner's "Portrait Song" Intervention}

\section{Types of "Portrait Songs"}

"Portrait Songs" are of several particular types: (1) "Community Songs," which instill a general sense of optimism and hope ("Rejoice"); (2) "Social Songs," which are tailored for specific recipients with targeted social goals ("Friendship"); (3) "Metaphoric Songs," which mirror a child's situation in a metaphoric, non-threatening, unobtrusive way ("Dreaming of a Jungle" and "The Comet Song"); and (4) "Action Songs," which push 
children beyond physical restrictions through acting out instructions. Individuals are influenced by the "Portrait Songs" beyond the individualized sessions since all types of "Portrait Songs" turn into "Community Songs" via group teaching, choir singing, public concerts, and recordings.

\section{The Therapist Role in the Songwriting Process}

Lerner's skills as a composer entail unique professional musicianship and years of compositional experience in and beyond the field of music therapy. She is both the lyricist and composer of her "Portrait Songs." She emphasizes a non-collaborative approach: "I do not let children compose my songs" (Vignette 6). Nevertheless, children demonstrate a natural impulse to improvise and self-initiated collaborative songwriting (Vignettes 5, 8).

\section{The Verbal Content of the "Portrait Songs": Making Audible Students Voices}

Children's authentic verbatim is often voiced in the lyrics. The compositional process begins with writing the lyrics, characteristically conveying targeted therapeutic contents, such as optimism, friendship, physical challenges, and other empathic messages with a sense of purpose. By using metaphors and poetic language, messages are often conveyed artistically and unobtrusively (Vignettes 8, 10).

\section{The Musical Content of the "Portrait Songs"}

Lerner's "Portrait Songs" are in the form of a Romantic period (19th Century) lied. Like a lied, a "Portrait Song" consists of two semiotic systems: music (voice and piano accompaniment) and language. This genre is paramount for Lerner. She declares: "For me, a lied is a natural mode of musical expression, an intuitive language. As a composer, I strive to reach the highest possible aesthetic level." The songs are professionally notated. The structure is usually strophic. Melodies are mostly kept within a 5-6 noterange so that children can sing them. The piano accompaniment is frequently based on broken chord figurations, tonal modulations, and chromatic progressions. The music never lacks a tonal center or key. In setting lyrics to music, verbal meanings are supported by various levels of the music, such as tempo, meter, rhythm, key, harmony, melodic flow, dynamics, articulation, expression and musical structure. Different tempi, rhythms, melodic contours, and harmonic progressions convey a whole gamut of emotions, such as hope, jubilation, joy, sadness, yearning, frustration, and desire.

\section{Interrelations between Teaching, Composition, and Music Therapy}

Music teaching, composing and therapy are intertwined and progress as in a "spiral scheme": the encounter with students is a source of inspiration for writing songs, songs become a pedagogical tool for music teaching and therapy, which creates a new source for writing a new song, and so on (Vignettes 7-8). Group lessons focus on promoting fundamental music-making skills through modeling and illustration (Vignettes 1, 5). Recipients (and peers) learn to sing the songs by ear being accompanied by the music therapist on the keyboard.

\section{The Impact of the "Portrait Song" Intervention on Lerner's pupils}

Lerner's "Portrait Songs" were a powerful pedagogical and therapeutic tool. "Portrait Songs" guided children to a mental attitude of optimism, hope, and confidence (Vignettes 1, 8-10), and to higher levels of social adjustment and interaction (Vignettes 2, 7). Motion songs refined physical skills and strengthened coordination and motor functions (Vignette 9). Songs assisted with areas of self-identity and self-efficacy (Vignettes 8-10). Withdrawn children benefited from the songs by receiving much attention, acceptance, and love (Vignettes 8, 10). The longitudinal "spiral scheme" process (teaching-composing-therapy) created a special bond between the composer-teacher- 
therapist and her pupils-recipients (Vignettes 8-10). Feedback sessions provided a framework for contact and communication, which allowed children to express their preference and taste and relate to relevant issues in their lives (Vignettes 3).

\section{Discussion and Implications}

\section{Creating "Portrait Songs" for Clients}

Lerner's innovative "Portrait Song" intervention in Israeli special education can give music therapists some perspectives about the possibility and benefits of composing complete therapeutic songs (lyrics and music) for specific clients. Clients who are unwilling and/or unable to co-operate in collaborative songwriting under the guidance of the therapist can benefit from "Portrait Songs" created by the therapist for them.

In addition to the practice of prompting clients to write lyrics and compose music (e.g., Baker et al., 2008; Lindberg, 1995; Silverman, 2011), therapists can write "Portrait songs" which convey resolutions for specific issues, including the issue of non-cooperation in collaborative songwriting. "Portrait Songs" might motivate those clients to work through and expediently resolve issues. "Motion Portrait Songs" composed by the therapist can become a valuable medium through which disabled patients might gain physical support. Through their compositions, therapists can provide clients with clear examples of self-invented songs which might encourage collaborative songwriting. As reviewed above, numerous rewards of engaging in songwriting activities were documented in the literature. A flexible combination of non-collaborative and collaborative songwriting strategies can provide a comprehensive approach of receptive-creative song-based music therapy. The clients' reflections on therapists' "Portrait Songs" can provide an avenue for communication and interaction. Participants might gain pleasure through singing both "Portrait Songs" and collaborative therapeutic songs individually and/or in groups. Public concerts and recordings of "Portrait Songs" and other collaborative therapeutic songs can prompt social acceptance and appreciation. They can also elicit a sense of pride, self-esteem, and accomplishment in clients.

\section{Afterthought}

Creating songs for therapy (including "Portrait Songs") is embedded in social interactions and human relations. The "Portrait Song" is actually participatory by nature since it is created and guided by social factors. Instead of the seeming dichotomy between collaborative and non-collaborative processes, we might consider songwriting as moving along a continuum ranging between personal and communal creative achievements while motivated by a common target toward the clients' support and well-being.

\section{Limitations of the Study}

The researcher's goal was to collect data in a way that imposed a minimal amount of personal bias. However, in creating the ethnographic account, one cannot escape the potential bias (and mistakes) in translating the verbatim and song lyrics.

Interviews with family members, caregivers, and other stakeholders were not conducted in this study. Such information and revisiting of the participants' perspectives, later on, would add robust to further study about the effectiveness of the "Portrait Song" intervention.

The implementation of the "Portrait Song" intervention in music therapy requires careful consideration. Therapists like "teachers are different personalities" (Zaare, 2012, p. 607). Some are composers by nature; others are more inclined to use pre-composed material. The "Portrait Song" implementation in music therapy is understandably unsystematic, drawing on the therapist's compositional experience and preferences. Furtherobservational studies can provide insights about song-based therapeutic work by examining the possibility of combining collaborative and non-collaborative songwriting attitudes. 


\section{Acknowledgments}

I express my gratitude to Prof. Judith Cohen and the music therapist Shmuel Ben-Dov (Spitzer) for their remarks. Special thanks to the two anonymous reviewers for their important comments and suggestions.

\section{About the Author}

Rivka Elkoshi is a pianist, senior lecturer of music at Levinsky College in Tel-Aviv, Israel and supervisor of doctoral dissertations at Bar-Ilan University, Ramat-Gan, Israel. She has taught music at undergraduate and postgraduate levels and conducted workshops for music educators on behalf of the Education Ministry in Israel. Her specialty is research on music perception and musical literacy, piano pedagogy and the Orff method. She is a recipient of an Institutional Fellowship for her research on children's musical perception. She has served as manager at the Israeli Musicology Society and presented internationally in a number of different countries. Her publications include piano compositions, several books on piano and Orff pedagogy, and book chapters and articles on music perception and musical literacy in international British and American journals.

\section{Notes}

1. For example, Aigen, 1997, 1998; Aldridge, 2005; Ansdell, 1995, 2010, 2014; Bailey, 1984; Baker et al., 2005; Baker, 2015, 2018; Brown \& Pavlicevic, 1997; Bruscia, 1996; Crowe, 2004; Dalton \& Krout, 2017; Derrington, 2005, 2011; Edgerton, 1990; Ficken, 1976; Gfeller, 1987; Goldstein, 1990; Jones, 2005; Lee \& Houde, 2011; Lee, 2003, 2014; Lindberg, 1995; Nordoff \& Robbins, 1962, 1968, 2007; O'Callaghan, 1996; Ortman, 1984; Plach, 1980; Priestley, 1985; Ritholz, 2014; Robarts, 2003; Roberts, 2006; Schmidt, 1983; Silverman, 2011; Streeter, 1999; Aasgaard \& Blichfeldt Ærø; Turry, 2006, 2014; Wilson, 2013.

2. For example, Turry (2006) studied songs that emerged during an eight-year course of musical treatment with Gloria, a woman diagnosed with non-Hodgkin's lymphoma. Robarts (2003) integrated psychodynamic therapy theory into her work, examining the improvised songs created with Lyndie, a girl who suffered early trauma.

3. The schools provide music therapy programs under the Israeli Special Education Laws (1988/2018). In 1988 the Special Education Law was legislated, aiming to advance and develop the skills and abilities of the special needs child (Meadan \& Gumpel, 2002). A reform was approved in 2018, about the integration of special-needs children in Israel's regular schools, including the decision that parents will decide whether their child attends a regular school or one for children with special needs (Kadari-Ovadia, 2019).

4. (C) All rights reserved to Stella Lerner (music and lyrics).

5. "The Song of Moses," for example, when the children of Israel cried out... being afraid "entangled in the land, the wilderness has shut them in" (Exodus 14:3; 14:10).

6. For example, "Here Comes the Sun" (1969), from the Beatles album Abbey Road. "Here comes the sun, and I sayit's all right." Staff members at hospitals in the New York metropolitan area have been playing songs like this song (The New York Times, May 20, 2020) long associated with finding joy through hard times.

7. The Japanese educator Shinichi Suzuki (1898-1998), the German composer Carl Orff (1895-1982), and the American music researcher Edwin Gordon (1927-2015) affirmed the efficiency of rote music teaching in various educational settings (Sarrazin, 2016).

8. Psychologist Albert Bandura is the researcher perhaps most often identified with learning through observation. Bandura's social learning theory proposed that learning can occur simply by observing the actions of others (Fryling et al., 2011).

9. In Hebrew, 'weak' [Kcalash] also means silent and slow. 


\section{References}

Aasgaard, T., \& Blichfeldt Ærø, S. C. (2016). Songwriting techniques in music therapy practice. In J. Edwards (Ed.), The Oxford handbook of music therapy. https://www.oxfordhandbooks.com/view/10.1093/oxfordhb/9780199639755.001.0001/ oxfordhb-9780199639755-e-20

Abra, J. (1994). Collaboration in creative work: An initiative for investigation. Creativity Research Journal, 7(1), 1-20.

Aigen, K. (1997). Here we are in music: One year with an adolescent, creative music therapy group. Barcelona Publishers.

Aigen, K. (1998). Paths of development in Nordoff-Robbins music therapy. Barcelona Publishers.

Aigen, K. (2009). Verticality and containment in song and improvisation: An application of schema theory to Nordoff-Robbins music therapy. Journal of Music Therapy, 46, 238-267.

Aldridge, D. (2005). Case study designs in music therapy. Jessica Kingsley.

Allwright, D. (1988). Observation in the classroom. Longman.

Amir, D. (2001). Music Therapy in Israel. Voices: A World Forum for Music Therapy, 1(1). https://doi.org/10.15845/voices.v1i1.39.

Ansdell, G. (1995). Music for life: Aspects of creative music therapy with adult clients. Jessica Kingsley.

Ansdell, G. (2010). How music helps in music therapy and everyday life. Routledge.

Ansdell, G. (2014). Revisiting 'Community music therapy and the winds of change' (2002): An original article and a retrospective evaluation. International Journal of Community Music, 7(1), 11-45. https://doi.org/10.1386/ijcm.7.1.11_1

Austin, D. (1999). Vocal improvisation in analytically oriented music therapy with adults. In T. Wigram, \& J. De Backer (Eds.), Clinical applications of music therapy in psychiatry (pp. 141-157). Jessica Kingsley Publishers.

Bailey, L. M. (1984). The use of songs in music therapy with cancer patients and their families. Music Therapy, 4(1), 5-17.

Baker, F. A. (2015). Therapeutic songwriting: Developments in theory, methods, and practice. Palgrave Macmillan.

Baker, F. A. (2016). The future of songwriting in music therapy. In C. Dileo (Ed.). Envisioning the future of music therapy, (1), (pp.123-130). Temple University Press.

Baker, F. A., Kennelly, J., \& Tamplin, J. (2005). Themes within songs written by people with traumatic brain injury: Gender differences. Journal of Music Therapy, 42(2), 111-122.

Baker, F. A., Stretton-Smith, P., Clark, I. N., Tamplin, J., \& Lee, Y. C. (2018). A group therapeutic songwriting intervention for family caregivers of people living with dementia: A feasibility study with thematic analysis. Frontiers in Medicine, 22(5), 151-178.

Baker, F. A., \& Wigram, T. (2005). Songwriting: Methods, techniques and clinical applications for music therapy clinicians, educators, and students. Jessica Kingsley Publishers.

Baker, F. A., Wigram, T., Stott, D., \& McFerran, K. (2008). Therapeutic songwriting in music therapy. Nordic Journal of Music Therapy, 17(2), 105-123.

Baker, F. A., Wigram, T., Stott, D., \& McFerran, K. (2009). Therapeutic songwriting in music therapy, part 2: Comparing the literature with practice across diverse clinical populations. Nordic Journal of Music Therapy, 18(1), 32-56.

Barrett, M. (2014). Collaborative creative thought and practice in music. Ashgate Publishing Limited.

Bepko, C., \& Krestan, J. (1993). Singing at the top of our lungs: Women, love and creativity. Harper Collins.

Bharucha, J. J., Curtis, M., \& Paroo, K. (2006). Varieties of musical experience. Cognition, 100, 131-172.

Biller, J. D., Olson, P .J., \& Breen, T. (1974). The effect of "happy" versus "sad" music and participation on anxiety. Journal of Music Therapy, 11(2), 68-73. 
Brantlinger, E., Jimenez, R., Klinger, J., Pugach, M, \& Richardson, V. (2005). Qualitative studies in special education. Exceptional Children, 71(2), 195-207.

Brown, S. \& Pavlicevic, M. (1997). Clinical improvisation in creative music therapy: Musical aesthetic and the interpersonal dimension. Arts in Psychotherapy, 23(5), 397 -405.

Bruscia, K. E. (1996). Defining music therapy. Barcelona Publishers.

Clinch, M. (2020). Italians are singing songs from their windows to boost morale during coronavirus lockdown. Health and Science. https://www.cnbc.com/2020/03/14/ coronavirus-lockdown-italians-are-singing-songs-from-balconies.html

Crowe, B. (2004). Music and soul making: Toward a new theory of music therapy. Scarecrow.

Dalton, T. A., \& Krout, R. E. (2005). Development of the Grief Process Scale through music therapy songwriting with bereaved adolescents. Arts in Psychotherapy, 32(2), 131-143.

Dalton, T. A., \& Krout, R. E. (2017). Using music therapy-based songwriting to support bereaved students. In J. A. Brown, \& S. R. Jimerson (Eds.), Supporting bereaved students at school (pp. 167-181). Oxford University Press.

Derrington, P. (2005). Teenager and songwriting: Supporting student in a mainstream secondary school. In F. A. Baker, \& T. Wigram (Eds.), Songwriting: Methods, techniques and clinical applications for music therapy clinicians, educators and students (pp. 68-81). Jessica Kingsley Publishers.

Derrington, P. (2011). Working with secondary-aged students who have complex emotional and behavioral difficulties. In A. Oldfield, J. Tomlinson, P. Derrington, \& J. Strange (Eds.), Music therapy in schools (pp. 195-211). Jessica Kingsley Publishers.

Dickey, M. (1992). A review of research on modeling in music teaching and learning. Bulletin of the Council for Research in Music Education, 113, 27-40.

Draves, T. J. (2008). Music achievement, self-esteem, and aptitude in a college songwriting class. Bulletin of the Council for Research in Music Education, 178, 35-46.

Edgerton, C. D. (1990). Creative group songwriting. Music Therapy Perspectives, 8, 15-19.

Ficken, T. (1976). The use of songwriting in a psychiatric setting. Journal of Music Therapy, 13(4), 163-172.

Fortune, A. E. (1987). Grief only? Client and social worker reactions to termination. Clinical Social Work Journal, 2, 159-171.

Fredrickson, B. (2001). The role of positive emotions in positive psychology: The broaden-andbuild theory of positive emotions. The American Psychologist, 56(3), 218-226.

Fryling, M. J., Johnston, C., \& Hayes, L. J. (2011). Understanding observational learning: An interbehavioral approach. The Analysis of Verbal Behavior, 27(1), 19-203. https://doi.org/ 10.1007/bf03393102

Gay, L. R., Mills, G. E., \& Airasian, P. W. (2011). Educational research: Competencies for analysis and applications (10th ed.). Pearson Education International.

Gebhard, J. G. (1999). Seeing teaching differently through observation. In J. G. Gebhard, \& R. Oprandy (Eds.), Language teaching awareness: A guide to exploring beliefs and practices (pp. 35-58). Cambridge University Press.

Gfeller, K. (1987). Songwriting as a tool for reading and language remediation. Music Therapy, 6(2), 28-38.

Goldstein, S. L. (1990). A songwriting assessment for hopelessness in depressed adolescents: A review of the literature and a pilot study. The Arts in Psychotherapy, 17(2), 117-124.

Gromko, J. E. (1996). In a child's voice: An interpretive interaction with young composers. Bulletin of the Council for Research in Music Education, 128, 37-58.

Grundblatt, A. (2016). Identifying, screening, and selecting group members. In C. Haen, \& S. Aronson (Eds.), Handbook of child and adolescent therapy: A practitioner reference (pp. 20-29). Routledge.

Hadley, R. T., Hadley, W. H., Dickens, V., \& Jordon, E. G. (2001). Music therapy: A treatment modality for special-needs populations. International Journal for the Advancement of Counselling, 23(3), 215-221. https://doi.org/1023/a:1013107909160 
Haston, W. (2007). Teacher modeling as an effective teaching strategy. Music Educators Journal, 93(4), 26. https://doi.org/10.2307/4127130

Hatampour, R., Zadehmohammadi, A., Masoumizadeh, F., \& Sedighi, M. (2011). The effects of music therapy on sensory motor functions of multiple handicapped people: Case study. Procedia-Social and Behavioral Sciences, 30, 1124-1126.

Heath, B., \& Lings, J. (2012). Creative songwriting in therapy at the end of life and in bereavement. Mortality, 17(2), 106-118. https://doi.org/10.1080/13576275.2012.673381

Hudgins, L. E. (2013). Closing time: Client's shared experiences of termination of a music therapy group in community mental health. Qualitative Inquiries in Music Therapy, 8, 51-78.

Janglo News, (2020, April 28). Israelis singing from their balconies on the eve of Israel's Memorial Day. Jerusalem Life. http://janglo.net/ index.php?option $=$ com_adsmanager\&page $=$ display\&catid $=99 \&$ tid $=482788$

Jones, J. D. (2005). A comparison of songwriting and lyric analysis techniques to revoke emotional change in a single session with people who are chemically dependent. Journal of Music Therapy, 42(2), 94-110.

Jones, J. D. (2006). Songs composed for use in music therapy: A survey of original songwriting practices of music therapists. Journal of Music Therapy, 43(2), 94-110.

Joyner, D. R. (1969). The monotone problem. Journal of Research in Music Education, 17, 115-124.

Kadari-Ovadia, S. (2019, August 6). Integration of special-needs kids in Israel's schools. MAD'AN, http://madan.org.il/en/news/integration-special-needs-kids-israels-schools

Kratus, J. (2016). Songwriting. Music Educators Journal, 102(3), 60-65.

Lane, D. (1988). Music therapy and oncology patients: The challenge and the response. Music Therapy with the Terminally Ill: The Next Step Forward (Symposium).

Lee, C. A. (2003). The architecture of Aesthetic Music Therapy. Barcelona Publishers.

Lee, C. A., \& Houde, M. (2011). Improvising in styles: A workbook for music therapists, educators, and musicians. Barcelona Publishers.

Lindberg, K. A. (1995). Songs of healing: Songwriting with an abused adolescent. Music Therapy, 13, 93-108.

Meadan, H., \& Gumpel, T. P. (2002). Special Education in Israel. https://www.nitzanisrael.org.il/media/408916/Special-Education-in-Israel.pdf

Moran, S., \& John-Steiner, V. (2004). How collaboration in creative work impacts identity and motivation. In D. Miell and K. Littleton (Eds.), Collaborative creativity: Contemporary perspectives (pp. 11-25). Free Association Books.

Nordoff, P., \& Robbins, C. (1962). Children's play-songs, first book. Theodore Presser.

Nordoff, P., \& Robbins, C. (1968). Children's play songs, second book. Theodore Presser.

Nordoff, P., \& Robbins, C. (2007). Creative music therapy: A guide to fostering clinical musicianship (2nd ed., revised \& expanded). Barcelona Publishers.

O'Callaghan, C. (1996). Lyrical themes in songs written by palliative care patients. Journal of Music Therapy, 33, 74-92.

Oldfield, A. (2005). Improvised songs and stories in music therapy diagnostic assessments as a unit for child and family psychiatry: A music therapist's and a psychotherapist's perspective. In F. Baker, \& T. Wigram, (Eds.), Songwriting:Methods, techniques and clinical applications for music therapy clinicians, educators and students (pp. 24-44). Jessica Kingsley Publishers.

Plach, T. (1980). The creative use of music in group therapy. Charles C. Thomas Publisher.

Priestley, M. (1985). Music therapy in action. MMB Music.

Repp, B. H. (1993). Music as motion: A synopsis of Alexander Truslit's (1938) Gestaltung und Bewegung in der Musik. Psychology of Music, 21, 48-72.

Riley, P. E. (2012). Exploration of student development through songwriting. Visions of Research in Music Education. http://www-usr.rider.edu/ vrme

Ritholz, M. S. (2014). The primacy of music and musical resources in Nordoff-Robbins music therapy. Music Therapy Perspectives, 32(1), 8-17. https://doi.org/10.1093/mtp/miu017 
Robarts, J. Z. (2003). The healing function of improvised songs in music therapy with a child survivor of early trauma and sexual abuse. In S. Hadley (Ed.), Psychodynamic music therapy: Case studies (pp. 141-182). Barcelona Publishers.

Robbins, S. (1991). Lexicalized metrical foot structure in maidu. In A. Mester, \& S. Robbins (Eds.), Phonology at Santa Cruz (pp. 95-116). Syntax Research Center University of California.

Roberts, M. (2006). I want to play and sing my story: Home-based songwriting for bereaved children and adolescents. The Australian Journal of Music Therapy, 17, 18-34.

Rolvsjord, R. (2005). Collaborations on songwriting with clients with mental health problems. In F. Baker, \& T. Wigram (Eds.), Songwriting: Methods, techniques and clinical applications for music therapy clinicians, educators and students (pp. 97-115). Jessica Kingsley.

Sarrazin, N. (2016). Music and the child: Approaches to music education. Milne Open Textbooks. https://milnepublishing.geneseo.edu/music-and-the-child/chapter/chapter-4/

Scherer, K. R., \& Zentner, M. R. (2001). Emotional effects of music: Production rules. In P. N. Juslin, \& J. A. Sloboda (Eds.), Music and emotion: Theory and research (pp. 361-392). Oxford University Press.

Schmidt, J. A. (1983). Songwriting as a therapeutic procedure. Music Therapy Perspectives, 1, 4-7.

Silverman, M. J. (2011). The effect of songwriting on knowledge of coping skills and working alliance in psychiatric patients: A randomized clinical effectiveness study. Journal of Music Therapy, 48(1), 103-122.

Smith, A., Duncan, J., \& Marshall, K. (2005). Children's perspectives on their learning: Exploring methods. Early Child Development and Care, 175(6), 473-487.

Smith, C. A., \& Morris, L. W. (1976). Effects of stimulative and sedative music on cognitive and emotional components of anxiety. Psychological Reports.

https://pubmed.ncbi.nlm.nih.gov/935310/

Stake, R. E. (2005). Qualitative case studies. In N. K. Denzin \& Y. S. Lincoln (Eds.), The Sage handbook of qualitative research (pp. 443-466). Sage Publications Ltd.

Stephensen, C., \& Baker, F. A. (2011). The role of music therapy in physical rehabilitation: A systematic literature review. Nordic Journal of Music Therapy, 20(1), 43-61.

Streeter, E. (1999). Finding a balance between psychological thinking and musical awareness in music therapy theory: A psychoanalytic perspective. British Journal of Music Therapy, 13(1), 5-20. https://doi.org/10.1177/135945759901300103

Studer, R., Gomez, P., Hildebrandt, H., \& Danuser, B. (2011). Stage fright: Its experience as a problem and coping with it. International Archives of Occupational and Environmental Health, 84, 761-771.

Swanson, A. L. (2020). Music therapy in schools: Stimulating the mind and body to create positive change. In C. Maykel \& M.A. Bray (Eds.), Promoting mind-body health in schools: Interventions for mental health professionals (pp. 233-244). American Psychological Association. https://doi.org/10.1037/0000157-016

Tamplin, J. (2006). Song collage technique: A new approach to songwriting. Nordic Journal of Music Therapy, 15, 177-190.

Turry, A. (1998). Transference and counter transference in Nordoff-Robbins music therapy. In K. Bruscia (Ed.), The dynamics of music psychotherapy (pp. 161-212). Gilsum, NH: Barcelona Publishers.

Turry, A. (2006). The interconnections between words and music in clinical improvisation. [Doctoral dissertation, New York University]. https://alanturry.com/dissertation

Turry, A. (2009). Integrating musical and psychological thinking: The relationship between music and words in clinically improvised songs. Music and Medicine, 1, 106-116.

Turry, A. (2010). Integrating musical and psychological thinking: The relationship between music and words in clinically improvised songs. Qualitative Inquiries in Music Therapy, 5, 116-172. 
Turry, A. (2014). Guest editorial. Music Therapy Perspectives, 32(1), 1-7. https://doi.org/ 10.1093/mtp/miu003

Viega, M. (2015). Exploring the discourse in hip hop and implications for music therapy practice. Music Therapy Perspectives, 34(2), 138-146.

Welch, G. F. (1986). A developmental view of children's singing. British Journal of Music Education, 3(03), 295. https://doi.org/10.1017/s0265051700000802

Wheeler, B. L., Shultis, C. L., \& Polen, D. W. (2005). Clinical training guide for the student music therapist. Barcelona Publishers.

Wilson, C. M. (2013). If you listen, I'll tell you how I feel: Incarcerated men expressing emotion through songwriting. Iowa Research Online: The University of Iowa's Institutional Repository. https://ir.uiowa.edu/cgi/viewcontent.cgi?article $=4978 \&$ context $=$ etd

Zaare, M. (2012). An investigation into the effect of classroom observation on teaching methodology. Social and Behavioral Sciences, 70, 605-614.

Zimmerman, B. J., \& Ghozeil, F. S. (1974). Modeling as a teaching technique. The Elementary School Journal, 74(7), 440-446.

\section{Appendix 1}

\section{"Rejoice"}

YouTube: $\quad$ https://www.youtube.com/watch?v=gzbRijtupVE\&t =65s\&ab_channel $=$ StellaLerner

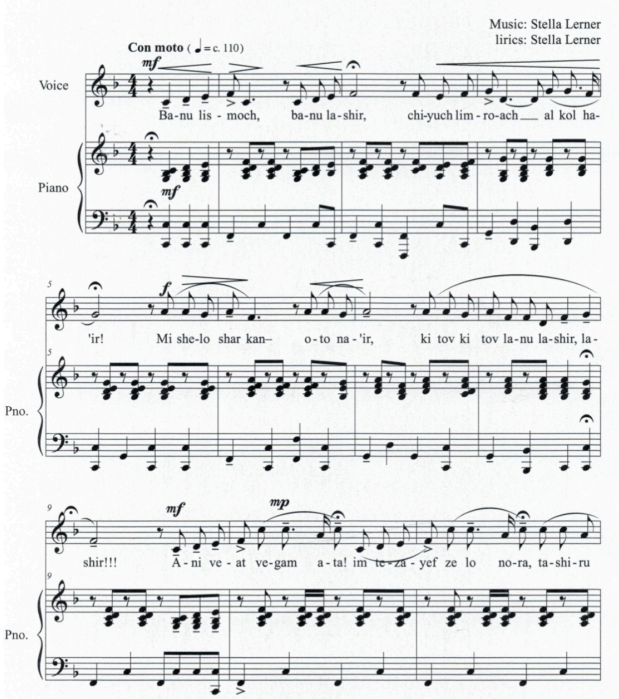

Figure 3

Rejoice (mm.1-11)

We came to rejoice, we came to chant

Smile happily; don't say you can't

If you stop we'll wake you up

Because it's good to sing and rap.

Me and you, we'll sing till noon

Don't worry if we're out of tune, 
Sing along no fear, no stress

Oh! Yes, yes...

Never fight to be the first

Everyone has lots of space

Sing along no fear, no stress

Oh! Yes, yes...

We're here to learn; be bright

Gain some knowledge, view, and sight

With desire and resolve

You and me,

Will be renewed, you'll see.

\section{"Friendship"}

YouTube: $\quad$ https://www.youtube.com/watch?v=lzyoF8s3HHc\&ab_channel=StellaLerner

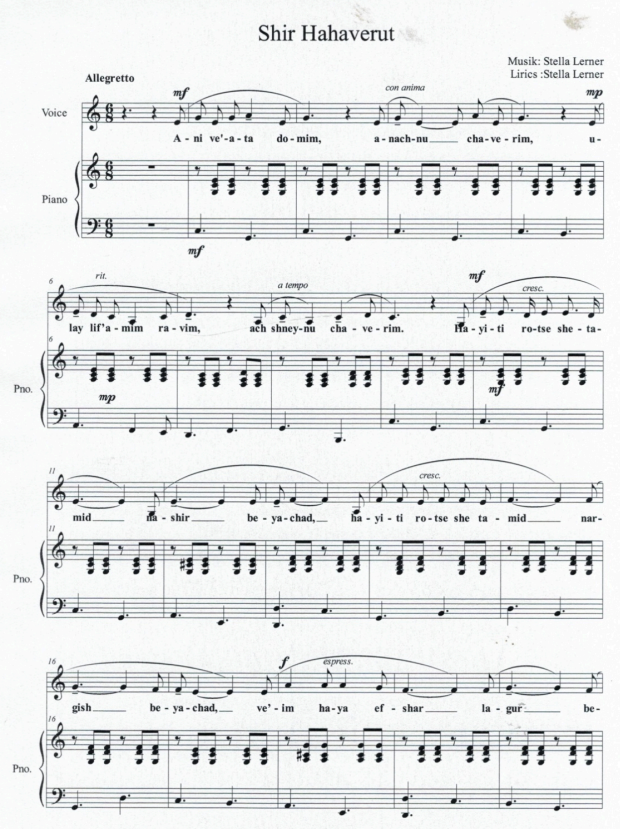

Figure 4

Friendship (mm.1-20)

We're alike; yes, we are friends, When we row we make amends. It's so good to be together, It's so good to sing together.

If we could have lived together, What a happy tie; a tether! Let us sing a friendship song, Everyone can sing along,

We are singing well together, We can be a team forever.

We're alike; yes, we are friends, When we row we make amends. We are friends! 


\section{"Dreaming of a jungle"}

YouTube: https://www.youtube.com/watch?v=gXV9vcJBABg\&ab_channel $=$ StellaLerner
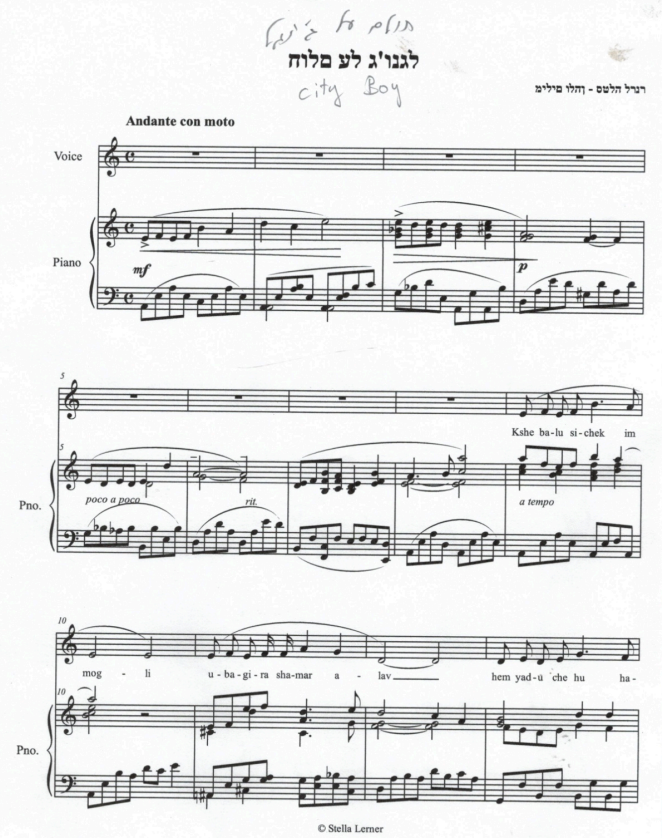

Figure 5

"Dreaming of the Jungle" (mm.1-13)

When Baloo played with Mowgli, And Bagheera kept him safe, They knew he was a wonder, A boy growing up in the woods. He was as strong as the wolves, Like Bagheera running and also He was smart as a kid, A boy who grew up in the city.

A boy in the woods

A kid in town,

The town is a human village,

A weird and cruel place

When Baloo played with Mowgli,

Baloo truly loved him

He wished to let him free

He wished to hug him like a big bear,

A good bear

A kid in a very sad city,

He cries: "Baloo!"

He always dreams of jungle

But stayed in his town

A wonder kid ... 


\section{"Dressing"}

YouTube: https://www.youtube.com/watch?v=5DULTcW-itA\&ab_channel = StellaLerner

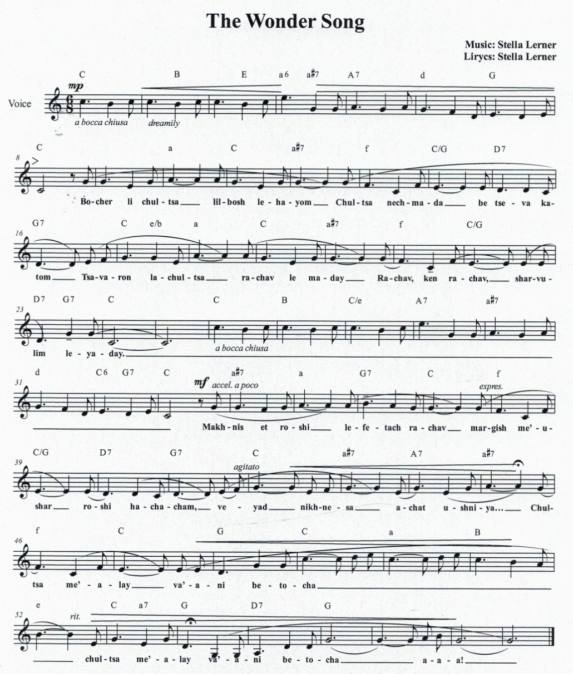

Figure 6

"Dressing"

A good-looking shirt

I'm wearing it today.

In yellow and gray

The collar is grand

Wide sleeve for my hand

Feel happy and bright!

My left hand and right

A shirt on my skin

And I am within!

\section{"The Comet Song"}

YouTube: https://www.youtube.com/watch?v =vH6kMBDDkkI\&ab_channel = StellaLerner 


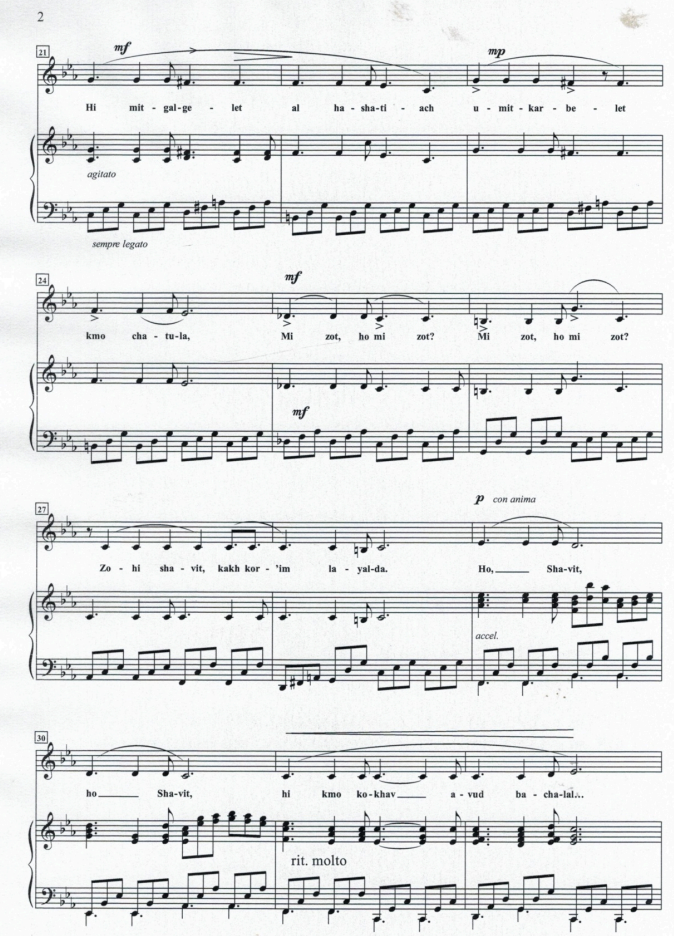

Figure 7

Lerner's "Comet Song" (mm.21-32)

Rolling on the carpet

Snuggling like a cat ...

Oh! What is that?

A star, a comet

Lost in space

So cold, so pale

Don't grasp her trail. 